\title{
Concurrent Signals and Behavioral Plasticity in Blue Crab (Callinectes sapidus Rathbun) Courtship
}

\author{
PAUL J. BUSHMANN* \\ Smithsonian Environmental Research Center, 647 Contee's Wharf Road, Edgewater, Maryland 21037
}

\begin{abstract}
Behavioral flexibility and behavioral regulation through courtship signals may both contribute to mating success. Blue crabs (Callinectes sapidus) form precopulatory pairs after courtship periods that are influenced by female and perhaps male urine-based chemical signals. In this study, male and female crabs were observed in $1.5-\mathrm{m}$ circular outdoor pools for $45 \mathrm{~min}$ while the occurrence and sequence of courtship behaviors and pairing outcomes were recorded. These results were then compared with trials in which males or females were blindfolded; lateral antennule (outer flagellum) ablated; blindfolded and lateral antennule ablated; or had received nephropore blocks. The relative importance of visual and chemical sensory systems during blue crab courtship were then determined and urine and non-urine based chemical signals for both males and females were examined. Courtship behaviors varied considerably in occurrence and sequence; no measured behavior was necessary for pairing success. Male or female blindfolding had no effect on any measured behavior. Males and females required chemical information for normal courtship behaviors, yet blocking male or female urine release did not affect courtship behaviors. Males required chemical information to initiate pairing or to maintain stable pairs. Male urine release was necessary for stable pairing, suggesting that male urine signals may be involved in pair maintenance rather than pair formation. Females that could not receive chemical information paired faster and elicited fewer male agonistic behaviors. The results demonstrate a great variability and flexibility in blue crab courtship, with no evidence for stereotyped behavioral sequences. However, these behaviors appear regulated by urine- and nonurine-based redundant chemical signals emanating from both males and females. Although urine-based signals play roles in blue
\end{abstract}

\section{Received 30 March 1998; accepted 1 June 1999}

* Current address: Anne Arundel Community College, 101 College Parkway, Arnold, MD 21012. E-mail: pjbushman@mail.aacc.cc.md.us crab courtship, chemical signals from other sites appear to carry sufficient information to elicit a full range of behavioral responses in males and females.

\section{Introduction}

Courtship and mating success depend upon correct behavioral responses by both males and females. One might expect a degree of plasticity in these behaviors (Hazlett, 1995). Because behavior can quickly track changes in environmental conditions (West-Eberhard, 1989), flexibility in the occurrence and timing of reproductive behaviors might help insure successful mating. Many invertebrates do exhibit plasticity in their behaviors (Carlson and Copeland, 1978; Dejean, 1987; Elner and Beninger, 1995) and this variability may be the rule for most animal species (Lott, 1991).

Conversely, one might also expect courtship and reproductive behaviors to be controlled and regulated by conspecific communication signals. By eliciting appropriate behavioral responses, these signals could enhance mating success and help to prevent interspecies mating. Courtship and mating in a fluctuating environment could be aided by multiple or redundant signals, which would make the transmission of adequate and correct information more likely. Multiple or redundant signals have been found in both invertebrate and vertebrate species (van den Hurk and Lambert, 1983; Linn et al., 1984; Rand et al., 1992).

Chemical communication signals appear to be nearly universal in the animal world. For aquatic crustaceans, chemical communication signals have been well documented in courtship and reproduction (Ryan, 1966; Atema and Engstrom, 1971; Eales, 1974; rev. in Dunham, 1978, 1988; Gleeson, 1980; Borowsky, 1984, 1985), while visual (Christy and Salmon, 1991) and acoustic (Salmon and Horch, 1972) signals have received less study. Recent studies with a variety of animal taxa have begun to examine 
multiple signals and signal interactions (Hazlett, 1982; Waas and Colgan, 1992; Stauffer and Semlitsch, 1993; Hughes, 1996).

Like many crustaceans (Hartnoll, 1969), the blue crab Callinectes sapidus Rathbun practices a polygynous mating system involving a complex coordination of female ecdysis, maturation, and copulation. The mating process has been well described (Hay, 1905; Churchill, 1921; Van Engel, 1958; Gleeson, 1980). Immature females nearing their final maturational molt, termed prepubertal females, are approached and courted by mature males. Pairing success results in females being held beneath males in a "cradle carry" posture for a period of precopulatory guarding. They are released for their molt, mated while still soft, and carried again for a period of postcopulatory guarding. This latter guarding protects the female while she is soft and prevents subsequent inseminations by other males (Jivoff, 1997a). Females are thought to receive only one copulation in their lifetime while males mate repeatedly (Van Engel, 1958), although multiple inseminations are possible and occur occasionally (Jivoff, 1997a).

Blue crab courtship can be divided into three phases: mate attraction, pair formation, and pair maintenance. In each phase a precise signaling system would seem important to help insure mating success. The coupling of molt and reproductive condition requires individuals to ascertain the physiological state of prospective partners. Signals can function in the reduction of agonistic behaviors (Tinbergen, 1953; Bastock, 1967), and during mating female blue crabs must in some way guard against injury or death by aggressive, cannibalistic males. Reproductive behaviors and sequences might, therefore, be tightly regulated by communication signals, making appropriate responses more likely and increasing the eventual mating success of the participants (Ryan, 1990; Reynolds, 1993).

Chemoreception and vision are the two best studied sensory modalities in blue crab courtship. Teytaud (1971) reported a role for visual signals in male recognition by pre-pubertal females. However, Gleeson (1980) showed that males did not respond to female visual stimuli alone, and pairing could proceed in darkness. Chemical signals are important for both male (Gleeson, 1980) and female (Teytaud, 1971; Gibbs, 1996) mate recognition. Some mature males respond with a courtship display to chemical compounds in pre-pubertal female urine (Gleeson, 1980; Gleeson et al., 1984) and reception of these chemical signals occurs via the aesthetasc sensilla on the lateral filament (outer flagellum) of the male antennules (Gleeson, 1982). This signaling theme appears common in crustaceans: urine carries chemical courtship signals (Ryan, 1966; Bushmann and Atema, 1997; Bamber and Naylor, 1997) and the antennules appear to be the site of distance chemoreception (Ache, 1975; Ameyaw-Akumfi and Hazlett, 1975; Devine and Atema, 1982; Cowan, 1991). The presence of a male chemical signal has not been firmly established, although Gleeson (1991) showed female attraction to water that contained males and Gibbs (1996) demonstrated disruption of pairing with male antennule ablation.

In this study, the occurrence and variability of courtship behaviors observed during blue crab pair formation were examined. These behaviors were then compared with those generated by male and female pairs with vision, distance chemoreception, both senses, or urine release impaired. This allowed a determination of the relative importance of visual and chemical sensory systems during blue crab courtship and an examination of urine- and nonurine-based chemical signals for both males and females.

\section{Materials and Methods}

Adult male crabs (125 mm-170 mm carapace width) were collected from the Rhode River, an upper Chesapeake Bay subestuary, with baited commercial crab traps. Premolt prepubertal females ( $96 \mathrm{~mm}-127 \mathrm{~mm}$ carapace width) were purchased from two local businesses which hold molting females for the soft crab industry. Females ranged in molt stage from late $D_{0}$ to $D_{3}$ (Drach, 1939). Animals were held in floating cages in the Rhode River or flow-through seawater tanks for no more than $48 \mathrm{~h}$ before participation in the study.

Behavioral interactions were observed in outdoor circular pools $(150 \mathrm{~cm} \mathrm{~d} . \times 20 \mathrm{~cm} \mathrm{~h}$.) with three centimeters of washed river sand as substrate. Prior to a trial, pools were filled with $15 \mathrm{~cm}$ of new river water filtered through a felt bag with $10 \mu \mathrm{m}$ mesh. A trial began by randomly selecting a male crab and placing him into a pool. Ten minutes later, a randomly selected prepubertal female was placed into the middle of the pool, inside an opaque plastic cylinder designed to prevent interactions prior to the start of the trial. After 10 min acclimation, the cylinder was removed, allowing the animals to freely interact. Three pools were started and watched simultaneously, and the ensuing behaviors were recorded by hand for $45 \mathrm{~min}$. Carapace width and molt stage were recorded for each animal.

Prior to trials either a male or a female from each pair was subjected to an experimental treatment. They were as follows:

1. Nephropore Occlusion: Blue crabs possess bilateral nephropores, located anteriorly and just ventral to the eye stalks. Each opening is found in a pit in the carapace. A chitinous flap opens to allow urine to exit. A modification of a successful cannulation technique was used to prevent urine release. Each pit was first dried by blotting and a drop of acetone, then filled with a viscous cyanoacrylate glue. The glue was immediately hardened with a catalytic accelerator. This sealed the nephropore flap shut. Animals were occluded $30 \mathrm{~min}$ prior to a trial. The blocks were 
checked for a tight bond with the carapace immediately before and after a trial. $\mathrm{n}=12$ males (M: URINE), 14 females (F:URINE).

3. Antennule Ablation: the distal lateral filament (outer flagellum), containing the aesthetasc sensilla, of both antennules was removed. $\mathrm{n}=12$ males $(\mathrm{M}$ : ANTENN), 12 females (F:ANTENN).

4. Blindfolding: two strips of black plastic $(50 \times 10 \mathrm{~mm})$ were fastened with cyanoacrylate glue to the dorsal and ventral carapace so that each wrapped over and covered an eye stalk. $n=13$ males (M:BLIND), 12 females (F:BLIND).

5. Antennule ablation and blindfolding: animals received both antennule ablation and blindfolding treatments. $\mathrm{n}=12$ males (M:ANT-BLIND), 12 females (F:ANTBLIND).

6. Sham treatment: both animals in a pair were subjected to sham operations. Antennules were held with forceps without ablation, nephropores were treated with acetone and accelerator but not glued, and blindfolds were attached similarly, but lateral to the eye stalks so that vision was not impaired. $\mathrm{n}=10$.

7. Intact: No treatments or sham operations were performed on either animal. $\mathrm{n}=12$.

Blue crab reproductive and agonistic behaviors have been well described over the years (Churchill, 1921; Van Engel, 1958; Teytaud, 1971; Jachowski, 1974; Gleeson, 1980). This study analyzed one agonistic and five reproductive behaviors. These behaviors were common, unmistakable, and reliable indicators of the nature of the interaction occurring. They were:

1. Male Strike: an agonistic behavior in which the male strikes or seizes any female body part with either chelae without subsequent attempts at cradle carry.

2. Male Display: A courtship behavior in which the male raises high on his walking legs, spreads his chelae laterally, and raises and rotates his 5 th walking legs (periopods) laterally.

3. Female Present: a courtship behavior in which the female faces away from the male and holds her body in a cradle carry posture, with or without spread chelae.

4. Female Rock: a courtship behavior in which the female rocks her body from side to side.

5. Initiation of Pair Formation: the male seizes the female and attempts to pull her into a cradle carry position. Females often resist, males may make many attempts, and pairing may or may not become established.

6. Stable Pair Formation: this was scored at the end of a trial. Pairs were in stable cradle carry if both female and male struggling had ceased, and the animals had been paired for at least $10 \mathrm{~min}$.
Comparisons of the intact and sham-treated groups showed no differences in the frequency of occurrence of any measured behavior or pairing outcome. These two groups thus appeared to represent samples of the same population and their data were pooled to yield 22 intact control trials. Behaviors of these pairs were examined to determine a normal range of behavioral variability and sequence. Behaviors were scored once if they occurred in a given trial. The number of trials in which behaviors occurred for the intact control group was then compared with those generated by the treatment groups. Overall differences between treatment and control groups were evaluated with a Chisquare test for multiple independent samples (Siegel and Castellan, 1988). Where significance was found, differences between specific treatment groups and the control were evaluated with a Fisher exact test (FAT) (Siegel and Castellan, 1988). The mean times between trial start and both the first behavioral interaction and Initiation of Pair Formation were also compared between the control and treatment groups. Overall differences were evaluated with analysis of variance (Jaccard, 1983), while mean differences between specific treatments and the control were evaluated with a non-directional $t$-test (Jaccard, 1983).

\section{Results}

Male and female blue crabs in intact control pairs showed great variability in the occurrence of their behaviors. During courtship, no behavior occurred with a high frequency (Table I). Male Strike, Male Display, Female Present and Female Rock occurred in only 41, 41, 56, and 36 percent of intact control trials, respectively. Pairing was initiated at a high rate, however ( $82 \%$ of trials), with $50 \%$ of trials resulting in Stable Pair Formation. No single behavior more likely led to the initiation of pairing or stable pairing, nor did the exhibition of any behavior preclude these outcomes (Table I). There was no single sequence of behaviors

\section{Table I}

Frequency of courtship and agonistic behaviors in intact blue crab pairs. The number of trials in which each behavior occurred is shown for all trials, those trials in which Initiation of Pair Formation occurred, and those trials in which a stable pair was formed

\begin{tabular}{|c|c|c|c|}
\hline Behaviors & $\begin{array}{l}\text { Occurrence in } \\
22 \text { trials }(\%)\end{array}$ & $\begin{array}{l}\text { Trials }(\%) \text { with } \\
\text { Initiation of } \\
\text { Pair Formation } \\
\quad(\mathrm{n}=18)\end{array}$ & $\begin{array}{c}\text { Trials }(\%) \text { with } \\
\text { Stable Pair } \\
\text { Formation } \\
(\mathrm{n}=11)\end{array}$ \\
\hline Male Strike & $9(41)$ & $6(33)$ & $2(18)$ \\
\hline Male Display & $9(41)$ & $10(56)$ & $3(30)$ \\
\hline Female Present & $12(56)$ & $10(56)$ & $4(36)$ \\
\hline Female Rock & $8(36)$ & $8(44)$ & $3(27)$ \\
\hline \multicolumn{4}{|l|}{ Initiation of Pair } \\
\hline Formation & $18(82)$ & - & - \\
\hline Stable Pair Formation & $11(50)$ & - & - \\
\hline
\end{tabular}




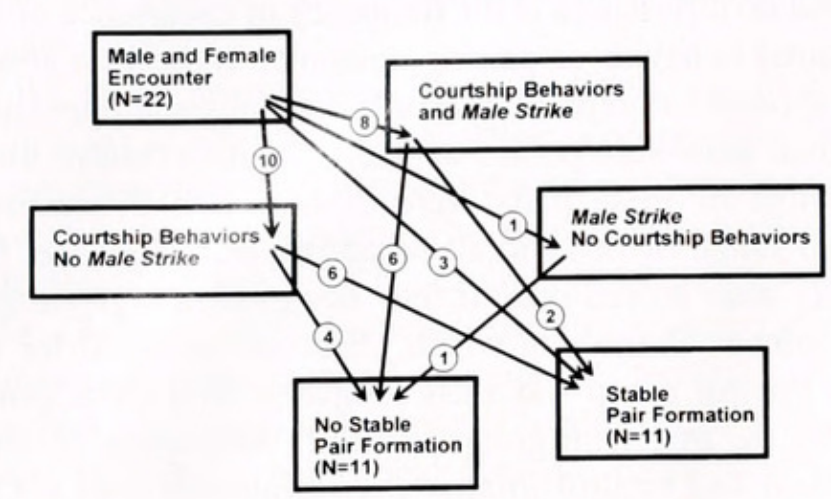

Figure 1. Flow chart showing behavioral pathways from first encounter, through courtship and/or male agonistic behavior, to stable pairing success or failure. The circled numbers represent the number of trials following that particular pathway

that predominated, nor any single sequence that invariably led to greater or lesser pairing success. Neither male or female courtship behaviors were correlated with female molt stage (early premolt $\mathrm{D}_{0}$ vs. late premolt $\mathrm{D}_{3}$ ) or the relative sizes of males and females.

However, some general trends emerge from courtship sequences examined together with male agonistic behavior (Fig. 1). Most pairs (18 of 22) exhibited some sequence of courtship behaviors prior to pair formation $\left(\chi^{2}=8.91, P=\right.$ $0.003)$. The presence of male agonistic behavior significantly reduced the likelihood of stable pairing (FAT, $P=$ 0.040). Of the nine pairs in which males exhibited Male Strike, only two (22\%) formed stable pairs. Of the remaining 13 pairs in which males did not exhibit Male Strike, nine $(69 \%)$ formed stable pairs (Fig. 1).

Examination of male agonistic and display behaviors revealed overall differences between treatment and control groups $\left(\chi^{2}=20.45, P<0.05 ; \chi^{2}=17.62, P<0.05\right)$. The incidence of Male Strike was significantly diminished (FAT, $P=0.009)$ if females were antennule ablated (F: ANTENN) (Fig. 2A). Scores for females antennule ablated and blindfolded (F:ANT-BLIND) closely approached significance (FAT, $P=0.050$ ). Male Display was significantly reduced when males were antennule ablated (M:ANTENN) (FAT, $P=0.009$ ) or antennule ablated and blindfolded (M:ANT-BLIND) (FAT, $P=0.049$ ), but were unaffected by female or male nephropore occlusion (F:URINE or M: URINE) (Fig. 2B). Blindfolding alone (M:BLIND and F:BLIND) had no effect on any measured behavior.

When the behaviors Female Present and Female Rock were examined, there were significant overall differences between treatment and control groups $\left(\chi^{2}=45.78, P<\right.$ $\left.0.05 ; \chi^{2}=20.2, P<0.05\right)$. The incidence of Female Present was reduced when females were antennule ablated (FAT, $P=0.035$ ) or antennule ablated and blindfolded
(FAT, $P=0.009$ ) (Fig. 2C). This behavior was also reduced by male antennule ablation (FAT, $P=0.001$ ). Female Rock (Fig. 2D) was reduced in incidence when females were antennule ablated and blindfolded (FAT, $P=0.009$ ); female antennule ablation alone did not significantly reduce the occurrence of this behavior $(P=0.083)$. Female Rock also occurred less frequently when males were antennule ablated and blindfolded (FAT, $P=0.009$ ). Male or female nephropore occlusions or blindfolding had no significant effect on either female courtship behavior.

Initiation of Pair Formation occurred frequently ( $80 \%$ of trials) in the intact control group (Fig. 2E). There were significant overall differences between groups in the occurrence of this behavior $\left(\chi^{2}=34.8, P<0.05\right)$. It occurred significantly less often than the control group when males were antennule ablated (FAT, $P=0.007$ ), while the reduction for antennule ablated and blindfolded males approached statistical significance $(P=0.062)$. Examination of stable pairing at the trials' conclusions showed significant overall differences between treatment groups $\left(\chi^{2}=31.36\right.$,

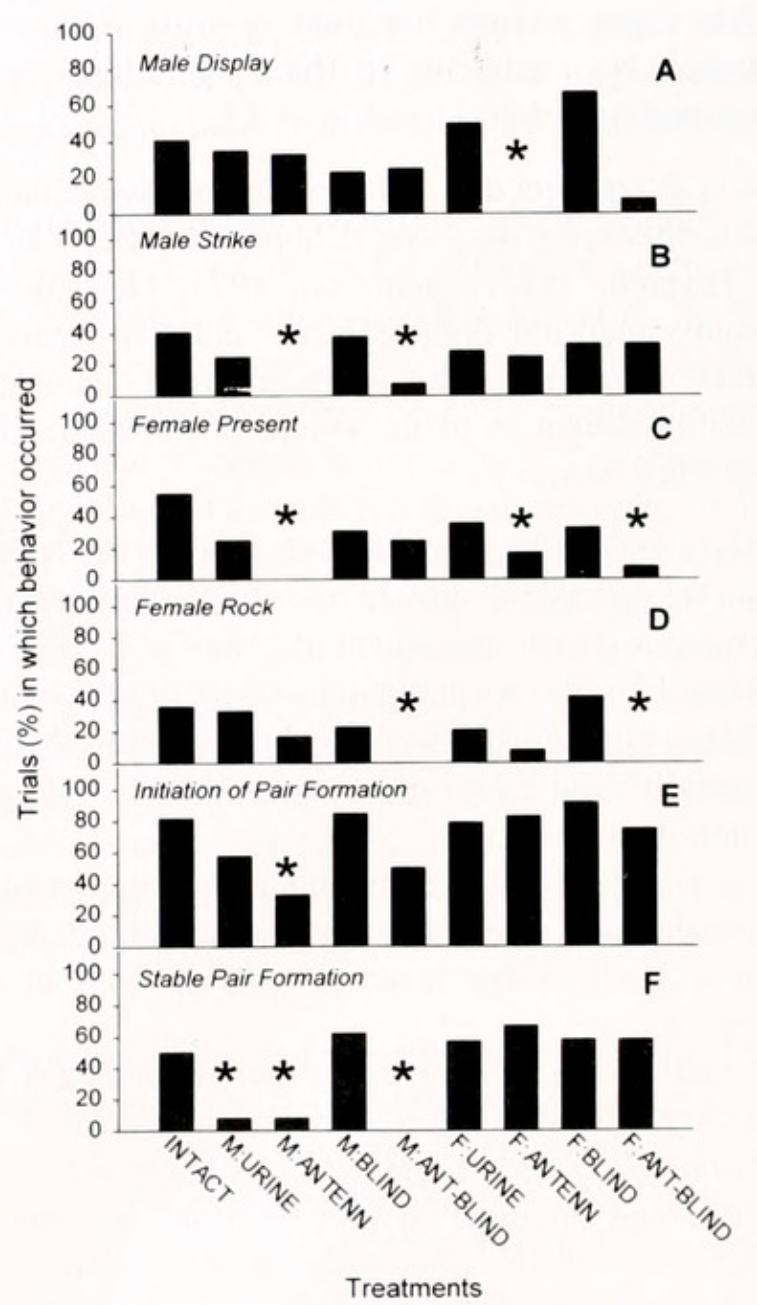

Figure 2. The percentage of trials in which Male Strike, (2A), Male Display (2B), Female Present (2C), Female Rock (2D), Initiation of Pair Formation (2E), and Stable Pair Formation (2F) occurred for the intact control and treatment groups. Differences between intact control and treatment groups were evaluated with a Fisher exact test. Stars indicate statistical significance at $\alpha=0.05$. 


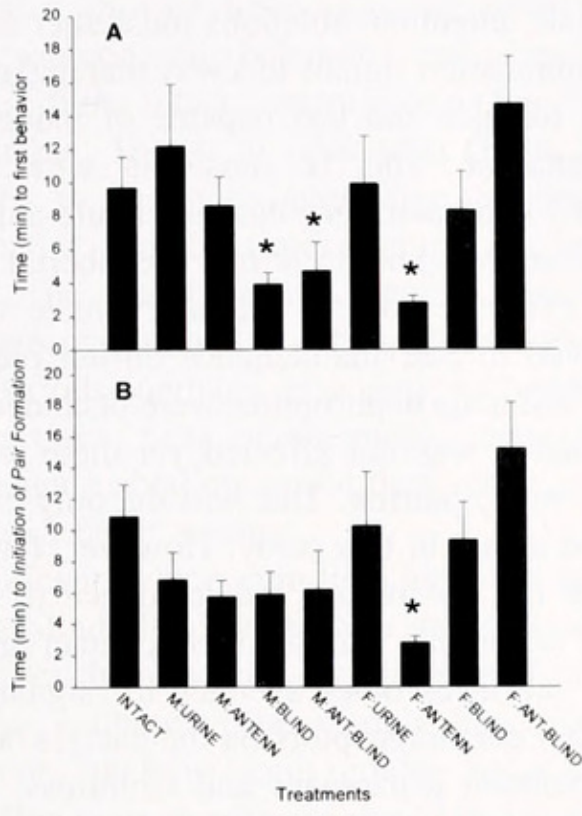

Figure 3. Mean time to first observed behavior (3A) and Initiation of Pair Formation (3B) for the intact control and treatment groups. Bars represent mean standard error. Differences between intact control and treatment groups were evaluated with a non-directional t-test. Stars indicate statistical significance at $\alpha=0.05$.

$P<0.05$ ). Fewer pairs were stable (Fig. $2 \mathrm{~F}$ ) if the males were antennule ablated (FAT, $P=0.016$ ) or antennule ablated and blindfolded (FAT, $P=0.002$ ). The incidence of stable pairing was also reduced when male nephropores were occluded (FAT, $P=0.016$ ). This was the only significant effect observed with any nephropore occlusion.

An examination of the mean time between a trial's start and the first observed behavior (Fig. 3A) showed significant differences between treatment groups (ANOVA $\mathrm{F}=2.73$, $P=0.009$ ). The mean time to first behavior was significantly less than the control group when males were blindfolded $(\mathrm{t}=2.97, P=0.026)$, when males were blindfolded and antennule ablated $(\mathrm{t}=2.28, P=0.032)$, and when females were antennule ablated $(\mathrm{t}=3.69, P=0.001)$. Overall differences were found (ANOVA $\mathrm{F}=2.29, P=$ 0.030 ) when the time between trial start and Initiation of Pair Formation was evaluated (Fig. 3B). In this comparison only the female antennule-ablated trials showed a significant reduction in time $(\mathrm{t}=3.90, P=0.001)$. Time differences between the male blindfolded group and the intact controls closely approached significance $(\mathrm{t}=2.01, P=$ 0.06 ), while those for the male blindfolded and antennule ablated group were not significant $(\mathrm{t}=1.46, P=0.170)$.

\section{Discussion}

Arthropod behavior has generally been considered stereotyped. Studies of some insects, such as many moth species, have demonstrated stereotypic courtship behavior: specific chemical signals elicit specific and predictable responses (Kaissling, 1979; Charlton and Cardé, 1990). Other insect species have shown greater flexibility, with individuals basing their behavioral responses upon current conditions and context (Carlson and Copeland, 1978; Dejean, 1987).

Similarly, the behavior of many crustacean species is not based upon stereotyped responses but instead shows great plasticity and can be modified as context changes (Ra' anan and Cohen, 1984; Elner and Beninger, 1995; Hazlett, 1995). The current study demonstrates such flexibility in Callinectes sapidus courtship behavior. Courtship is variable in that no single behavior must occur, nor does any behavior invariably lead to successful pairing. No single behavior occurred more than approximately half the time, yet the odds of successful pairing remained high. This suggests that courtship follows multiple behavioral pathways, all potentially leading to successful pair formation. Such flexible courtship would be useful for both males and females in a species that mates in a fluctuating estuarine environment. With intense male competition for females (Jivoff, 1997b) and only one chance for females to receive sperm, it maximizes the chances of an encounter producing pair formation, with eventual mating and reproductive success.

However, blue crab mating behavior is not without constraints and regulation. In the intact control group most pairs displayed some courtship behaviors prior to pair formation, and male agonistic behavior reduced the likelihood of stable pairing. This demonstrates the importance of controlling male aggression during courtship and, together with the treatment trials, illustrates the role that communication signals often serve in this regard (Tinbergen, 1953). For blue crabs, the most likely path to successful pairing, and therefore successful reproduction, involves courtship and reduced male aggression.

The treatment trials suggest behavioral regulation through chemical communication signals and that both female and male chemical signals play important roles in courtship and pairing. Males with ablated antennules showed reduced instances of Male Display, Initiation of Pair Formation and Stable Pair Formation. For the male, loss of distance chemoreception affected behavioral expression and directly reduced courtship success. The relevant chemical information did not seem to reside solely in female urine, however, because females with occluded nephropores induced male behaviors at frequencies similar to intact controls. Although the results were less clear, females also appeared to exhibit fewer instances of courtship behaviors when their antennules were ablated, while pairing initiation or stability was unaffected. The physical act of pairing is initiated by the male, and evidently an antennule-ablated female is still attractive to males. However, an unreceptive female can likely flee and decline pairing in the wild. Blocking male urine release had no effect on female courtship behaviors, again suggesting that the relevant chemical compounds are not restricted to urine. 
It is now generally recognized that many chemical signals are mixtures or blends and thus can serve as multiple or redundant signals (van den Hurk and Lambert, 1983; Vetter and Baker, 1983; Linn et al., 1984). In blue crabs and other brachyurans, a chemical signal in female urine that induces male courtship behavior has been well described (Ryan, 1966; Gleeson, 1980; Seifert, 1982; Bamber and Naylor, 1997). The present study does not refute the existence of this signal, but rather suggests urine is only one source of courtship signals and is not obligatory for the initiation of male or female courtship behaviors. There appears to be chemical information from non-urine sources capable of eliciting the same behaviors when nephropores are occluded. It is only when all chemical signals are lost through antennule ablation that behavior is negatively affected. These statements appear at odds with Ryan's (1966) work showing no male responses to seawater that had contained nephropore-blocked premolt Portunus sanguinolentus females. It may be that the relevant female $P$. sanguinolentus signal is sent only in urine. In addition, the females in Ryan's study were isolated in 8-1 buckets during signal release, while females in the current study were placed in larger tanks in the presence of a male. This more naturalistic behavioral context may have elicited female nonurine signal release and male responses not seen in the earlier study. Lastly, Ryan used molten paraffin rather than glue as blocks; this may have affected the animals differently from the blocks used here. These apparent interspecific differences in behaviors and signals should be more closely examined.

Blue crab courtship thus appears regulated by female and male concurrent chemical signals emanating from multiple sources. It is unknown if the concurrent signals demonstrated here are different compounds or if they are the same compound released at different sites. This knowledge awaits the purification and structural description of these chemical courtship signals. The release sites of the non-urine chemical compounds are likewise unknown. In lobsters (Homarus americanus), the gill current has been implicated as a method for transporting chemical signals to a receiver (Atema, 1985). Because blue crabs possess a similar current, it is possible that the gills themselves or structures within the gill cavity are sources of chemical signals. Tegumental glands, found in blue crabs and other arthropods (Johnson, 1980; Talbot and Demers, 1993) have been suggested as chemical signal sources in several crustacean species (Berry, 1970; Kamiguchi, 1972; Bushmann and Atema, 1996) and also may play a role here.

Loss of chemical signals in some instances had indirect effects on behavior. Males were less aggressive toward antennule-ablated females. Ablation evidently alters either female behavior or her signaling patterns in a way that affects male agonistic behavior. Similarly, female courtship behaviors were reduced when male chemical reception was impaired. Male antennule ablations must alter male behaviors or communication signals in a way that makes them less attractive to females and less capable of inducing female courtship behavior. This is consistent with field work (Gibbs, 1996) demonstrating that antennule-ablated males in crab traps are less able to attract prepubertal females.

There is evidence for an obligatory male urine-based signal involved in pair maintenance during precopulatory guarding. When male nephropores were occluded, initiation of pair formation was not affected yet there was reduced incidence of stable pairing. This was the only evidence for a urine-based signal in this study. However, female antennule ablation did not reduce the incidence of stable pair formation. It is possible that the direct contact involved in a cradle carry produces other avenues for signal reception, such as contact chemoreceptors on the dactyls or elsewhere on the exoskeleton (Fuzessery and Childress, 1975). Although the observed reduction in stable pairing could have resulted from some male trauma associated with the occlusion procedure, occluding females produces no such pattern and blue crabs and lobsters appear capable of suspending urine release for periods of several hours without ill effect (Bushmann, unpub. data, Breithaupt and Atema, 1993).

Visual signals seem to play no role in influencing courtship behaviors or outcomes. Blindfolded males and females courted, received courtship, and paired with success rates equal to the intact controls. This is consistent with previous observations for blue crabs and lobsters that visual signals are of secondary importance during social interactions (Gleeson, 1980; Snyder et al., 1993; Kaplan et al., 1993). Thus, the primary function of the male courtship display is likely not transmission of a visual signal. However, it may be an excellent method for transmitting both chemical and hydrodynamic signals to a potential partner. Rotation of the periopods causes a strong and highly turbulent flow of water directed forward of the animal (Gleeson, 1991; Bushmann, unpub. data). This flow would likely entrain any chemical signal emanating from the gills or nephropores. In addition, some crustaceans use hydrodynamic information during agonistic interactions and prey capture (Barron and Hazlett, 1989; Breithaupt et al., 1995). The highly turbulent, directed flow generated by male paddle waving could provide directional or other information to females.

Many aspects of the male courtship display remain unclear. It must have some energetic cost and may draw attention by predators, yet it need not occur for successful pairing and occurred in less than half the observed encounters. In this study its occurrence was not correlated with female premolt stage, the relative sizes of males and females, or pairing success during the encounter. The function of this rather spectacular behavior and the stimuli leading to its initiation require further investigation.

Loss of female chemoreception appeared to accelerate rather than retard pairing. When females were antennule- 
ablated, males showed little agonistic behavior, females exhibited fewer courtship behaviors, and pairs formed more quickly than in the intact control group (Fig. 3B) and they remained stable. This is at odds with Gibbs (1996), who found males to be more aggressive toward antennuleablated females and the time required for pairing to be unaffected. The present study suggests that females use chemical information and courtship behaviors to lengthen courtship periods, perhaps as a way of better evaluating potential partners. Loss of chemical information through female antennule ablation would then result in less female evaluation and faster pairing.

The significant reduction in time until first behavior seen in the male blindfolded group was probably a general behavioral rather than specific communication effect. Blindfolded males, without visual stimuli, may have been less wary and more likely to begin moving about the pool after trial start. This male movement would result in more rapid encounters with females. The time until Initiation of Pair Formation was not significantly shortened, however (Fig. 3B), and blindfolding had no effect on any measured behavior.

Several studies have shown that lateral antennule ablation affects behavior by interfering with chemical reception (Ache, 1975; Ameyaw-Akumfi and Hazlett, 1975; Gleeson, 1980; Cowan, 1991). However, in any ablation experiment there is always a question of false-negative responses due to a general dampening of behavior caused by the procedure itself (Dunham, 1978). In the present study, while ablated males showed reduced reproductive behaviors, agonistic responses were unaltered. Antennule-ablated females, while not exhibiting many courtship behaviors, were nonetheless courted and carried by males. These ablations appeared to affect certain reproductive behaviors, presumably those dependent upon chemical signals, rather than causing a general reduction in behavioral responses.

A second potential problem concerns the blocks applied to the nephropores to prevent urine release. Correct interpretation of results depends upon an effective block. Several lines of evidence suggest that these blocks prevented urine release. First, they are the initial step in the attachment of a urine cannula. This cannula can collect urine from blue crabs for several days without leaking (Bushmann, unpub. data). Second, three urine blocked animals were held after their trials. These individuals were swollen from fluid retention within $6 \mathrm{~h}$ and died within $12 \mathrm{~h}$. Lastly, the water from four blocked animals held individually in 2-1 tanks showed reduced ammonia levels compared to water from four unblocked crabs (Bushmann, unpub. data). Ammonia levels from blocked crab water were not zero, because ammonia is also excreted across the gills (Mantel and Farmer, 1983). Taken together, these observations suggest that the blocks used in this experiment were effective in preventing urine release.
In summary, Callinectes sapidus courtship illustrates both behavioral plasticity and the importance of behavioral regulation through a signaling system. The concurrent and seemingly redundant chemical signals discussed here may be different compounds or the same compound released from different sites. Chemical rather than visual signals from both male and female seem to play crucial roles in courtship and pairing. Although these signals influence the initiation of behaviors and pairing success, there appear to be many different pathways leading to pairing success, and no single behavior and perhaps no single signal is necessary for pairing success. Courtship behaviors and chemical signaling may operate in a more complex and flexible manner than previously demonstrated.

\section{Acknowledgments}

The author thanks Dr. Anson H. Hines for his assistance, support, and review of this manuscript. This work was funded through a Smithsonian Postdoctoral Fellowship to $\mathrm{PB}$, and an NSF grant OCE-9711843 to AHH.

\section{Literature Cited}

Ache, B. W. 1975. Antennular mediated host location by symbiotic crustaceans. Mar. Behav. Physiol. 3: 125-130.

Ameyaw-Akumfi, C., and B. A. Hazlett. 1975. Sex recognition in the crayfish Procambarus clarkii. Science 190: 1225-1226.

Atema, J. 1985. Chemoreception in the sea: adaptations of chemoreceptors and behavior to aquatic stimulus conditions. Soc. Exp. Biol. Semin. Ser. 39: 387-423.

Atema, J., and D. G. Engstrom. 1971. Sex pheromone in the lobster. Homarus americanus. Nature 232: 261-263.

Bamber, S. D., and E. Naylor. 1997. Sites of release of putative sex pheromone and sexual behaviour in female Carcinus maenas (Crustacea: Decapoda). Estuarine, Coastal Shelf Sci. 44: 195-202.

Barron, L. C., and B. A. Hazlett. 1989. Directed currents: a hydrodynamic display in hermit crabs. Mar. Behav. Physiol. 15: 83-87.

Bastock, M. 1967. Courtship: an Ethological Study. Aldiline Publishing Company, Chicago.

Berry, P. F. 1970. Mating behavior, oviposition and fertilization in the spiny lobster Panulirus homarus (Linnaeus). South African Association for Marine Biological Research Investigational Report no. 24, 16 pp.

Borowsky, B. 1984. Effects of receptive females' secretions on some male reproductive behaviors in the amphipod crustacean Microdeutopus gryllotalpa. Mar. Biol. 33: 266-271.

Borowsky, B. 1985. Responses of the amphipod crustacean Gammarus palustis to waterborne secretions of conspecifics and congenerics J. Chem. Ecol. 11: 1545-1552

Breithaupt, T., and J. Atema. 1993. Evidence for the use of urine signals in agonistic interactions of the American lobster. Biol. Bull. 185: 318

Breithaupt, T., B. Schmitz, and J. Tautz. 1995. Hydrodynamic orientation of crayfish (Procambarus clarkii) to swimming fish prey J. Comp. Physiol. A 177: 481-491.

Bushmann, P., and J. Atema. 1996. Nephropore rosette glands of the 
lobster Homarus americanus: possible sources of urine pheromones. $J$. Crustac. Biol. 16(2): 221-231.

Bushmann, P., and J. Atema. 1997. Shelter sharing and chemical courtship signals in the lobster, Homarus americanus. Can. J. Fish. Aquat. Sci. 54(3): 647-654.

Carlson, A. D., and J. Copeland. 1978. Behavioral plasticity in the flash communication systems of fireflies. Am. Sci. 66(3): 340-346.

Charlton, R. E., and R. T. Card(943e. 1990. Behavioral interactions in the courtship of Lymantria dispar (Lepidoptera: Lymantriidae). Ann. Entomol. Soc. Am. 83(1): 89-96.

Christy, J. H., and M. Salmon. 1991. Comparative studies of reproductive behavior in mantis shrimps and fiddler crabs. Am. Zool. 31: 329-337

Churchill, E. P., Jr. 1921. Life history of the blue crab. Bull. U.S. Bur. Fish. 36: 95-128.

Cowan, D. F. 1991. The role of olfaction in courtship behavior of the American lobster Homarus americanus. Biol. Bull. 181: 402-407.

Dejean, A. 1987. Behavioral plasticity of hunting workers of Serrastruma serrula (Hymenoptera: Formicidae, Myrmicinae) presented with different arthropods. Sociobiology 13(3): 191-208,

Devine, D. V., and J. Atema. 1982. Function of chemoreceptor organs in spatial orientation of the lobster, Homarus americanus: differences and overlap. Biol. Bull. 163: 144-153.

Drach, P. 1939. Mue et cycle d'intermue chez les crustaces decapodes. Ann. Inst. Oceanogr. 19: 103-391.

Dunham, P. J. 1978. Sex pheromones in Crustacea. Biol. Rev. Camb. Philos. Soc. 53: 555-583.

Dunham, P. J. 1988. Pheromones and behaviour in Crustacea. Pp. 375-392 in Endocrinology of Selected Invertebrate Types, H. Laufer and G. H. Downer, eds. Liss, New York.

Eales, A. J. 1974. Sex pheromone in the shore crab Carcinus maenas, and the site of its release from females. Mar. Behav. Physiol. 2: 345-355.

Elner, R. W., and P. G. Beninger. 1995. Multiple reproductive strategies in snow crab, Chionoecetes opilio: Physiological pathways and behavioral plasticity. J. Exp. Mar. Biol. Ecol. 193: 93-112.

Fuzessery, Z. M., and J. J. Childress. 1975. Comparative chemosensitivity to amino acids and their role in the feeding activity of bathypelagic and littoral crustaceans. Biol. Bull. 149: 522-538.

Gibbs III, D. S. 1996. Field and laboratory evidence of pheromone mediated mating behavior in the blue crab, Callinectes sapidus. M.S. thesis, The College of William and Mary.

Gleeson, R. A. 1980. Pheromone communication in the reproductive behavior of the blue crab, Callinectes sapidus. Mar. Behav. Physiol. 7: $119-134$

Gleeson, R. A. 1982. Morphological and behavioral identification of the sensory structures mediating pheromone reception in the blue crab, Callinectes sapidus. Biol. Bull. 163: 162-171.

Gleeson, R. A. 1991. Intrinsic factors mediating pheromone communication in the crab Callinectes sapidus. Pp. 17-32 in Crustacean Sexual Biology, R. T. Baur and J. N. Martin, eds. Columbia University Press, New York

Gleeson, R. A., M. A. Adams, and A. B. Smith III. 1984. Characterization of a sex pheromone in the blue crab, Callinectes sapidus: Crustecdysone studies. J. Chem. Ecol. 10: 913-921.

Hartnoll, R. G. 1969. Mating in the Brachyura. Crustaceana 16: 161181 .

Hay, W. P. 1905. The life history of the blue crab (Callinectes sapidus). Rep. U.S. Bur. Fish. 1904: 395-413.

Hazlett, B. A. 1982. Chemical induction of visual orientation in the hermit crab Clibanarius vittatus. Anim. Behav. 30(4): 1259-1260.

Hazlett, B. A. 1995. Behavioral plasticity in crustacea: why not more? J. Exp. Mar. Biol. Ecol. 193: 57-66.
Hughes, M. 1996. The function of concurrent signals: visual and chemical communication in snapping shrimp. Anim. Behav. 52: 247-257.

Jaccard, J. 1983. Statistics for the Behavioral Sciences. Wadsworth, Belmont, CA

Jachowski, R. L. 1974. Agonistic behavior of the blue crab, Callinectes sapidus Rathbun. Behaviour 50: 232-253.

Jivoff, P. 1997a. The relative roles of predation and sperm competition on the duration of the post-copulatory association between the sexes in the blue crab, Callinectes sapidus. Behav. Ecol. Sociobiol. 40: 175185

Jivoff, P. 1997b. Sexual competition among male blue crab, Callinectes sapidus. Biol. Bull. 193: $368-380$.

Johnson, P. T. 1980. Histology of the Blue Crab, Callinectes sapidus. A Model for the Decapoda. Praeger Publishers, New York.

Kaissling, K. E. 1979. Recognition of pheromones by moths, especially in saturnids and Bombyx mori. Pp. 43-56 in Chemical Ecology: Odour Communication in Animals, F. J. Ritter, ed. Elsevier, Amsterdam.

Kamiguchi, Y. 1972. A histological study of the "sternal gland" in the female freshwater prawn, Palaemon paucidens, a possible site of origin of the sex pheromone. J. Fac. Sci. Hokkaido Univ. Ser. VI, Zool. 18(3): $356-365$

Kaplan, L. J., C. Lowrance, J. Basil, and J. Atema. 1993. The role of chemical and visual cues in agonistic interactions of the American lobster. Biol. Bull. 185: 320-321.

Linn, C. E., L. B. Bjostad, J. W. Du, and W. L. Roelofs. 1984. Redundancy in a chemical signal: behavioral responses of male Trichoplusia ni to a 6-component sex pheromone blend. J. Chem. Ecol. 10(11): 1635-1658.

Lott, D. F. 1991. Intraspecific Variation in the Social Systems of Wild Vertebrates. Cambridge University Press, Cambridge.

Mantel, L. H., and L. L. Farmer. 1983. Osmotic and ionic regulation. Pp. 53-161 in The Biology of Crustacea Vol. 5, L. H. Mantel, ed. Academic Press, New York.

Ra'anan, Z., and D. Cohen. 1984. The effect of group interactions on the development of size distribution in Macrobrachium rosenbergii (de Man) juvenile populations. Biol. Bull. 166: 22-31.

Rand, A. S., M. J. Ryan, and W. Wilczynski. 1992. Signal redundancy and receiver permissiveness in acoustic mate recognition by the Túngara frog, Physalaemus pustulosus. Am. Zool. 32: 81-90.

Reynolds, J. D. 1993. Should attractive individuals court more? Theory and test. Am. Nat. 14: 914-927.

Ryan, E. P. 1966. Pheromone: evidence in a decapod crustacean. Science 151: $340-341$

Ryan, M. J. 1990. Sexual selection, sensory systems and sensory exploitation. Oxf. Surv. Evol. Biol. 7: 157-195.

Salmon, M., and K. W. Horch. 1972. Acoustic signalling and detection by semi-terrestrial crabs of the family Ocypodidae. Pp 60-96 in Behavior of Marine Animals. Current Perspectives in Research, Vol. 1, Invertebrates. H. E. Winn and B. L. Olla, eds. Plenum Press, New York.

Seifert, P. 1982. Studies on the sex pheromone of the shore crab. Carcinus maenas, with special regard to ecdysone excretion. Ophelia 12(2): 147-158.

Siegel, S., and N. J. Castellan Jr. 1988. Nonparametric Statistics for the Behavioral Sciences. 2nd ed. McGraw-Hill, New York.

Snyder, M. J., C. Ameyaw-Akumfi, and E. S. Chang. 1993. Sex recognition and the role of urinary cues in the lobster, Homarus americanus. Mar. Behav. Physiol. 24: 101-116.

Stauffer, H. P., and R. D. Semlitch. 1993. Effects of visual, chemical and tactile cues of fish on the behavioural responses of tadpoles. Anim. Behav. 46: 355-364.

Talbot, P., and D. Demers. 1993. Tegumental glands of crustacea. Pp. 
151-191 in The Crustacean Integument. M. N. Horst and J. A. Freeman, eds. CRC Press, Boca Raton.

Teytaud, A. R. 1971. The laboratory studies of sex recognition in the blue crab, Callinectes sapidus Rathbun. Sea Grant Technical Bulletin No. 156. University of Miami Sea Grant Program. 62 pp.

Tinbergen, N. 1953. Social Behaviour in Animals with Special Reference to Vertebrates. Chapman and Hall, London.

Van den Hurk, R., and J. G. D. Lambert. 1983. Ovarian steroid gluconurides function as sex pheromones for female zebrafish, Brachydanio rerio. Can. J. Zool. 61: 2381-2387.

Van Engel, W. A. 1958. The blue crab and its fishery in Chesapeake
Bay. Part I-Reproduction, early development, growth and migration. Commer. Fish. Rev. 20: 6-17.

Vetter, R. S., and T. C. Baker. 1983. Behavioral responses of male Heliothis virescens in a sustained-flight tunnel to combinations of seven compounds identified from female sex pheromone glands. J. Chem. Ecol. 9: 747-759.

Waas, J. R., and P. W. Colgan. 1992. Chemical cues associated with visually elaborate aggressive displays of three-spine sticklebacks. J. Chem. Ecol. 18(2): 2277-2284.

West-Eberhard, M. J. 1989. Phenotypic plasticity and the origins of diversity. Annu. Rev. Ecol. Syst. 20: 249-278. 


\section{$2 \mathrm{BHL}$ Biodiversity Heritage Library}

Bushmann, Paul J. 1999. "Concurrent Signals and Behavioral Plasticity in Blue Crab (Callinectes sapidus Rathbun) Courtship." The Biological bulletin 197, 63-71. https://doi.org/10.2307/1542997.

View This Item Online: $\underline{\text { https://www.biodiversitylibrary.org/item/17268 }}$

DOI: https://doi.org/10.2307/1542997

Permalink: https://www.biodiversitylibrary.org/partpdf/19384

\section{Holding Institution}

MBLWHOI Library

\section{Sponsored by}

MBLWHOI Library

\section{Copyright \& Reuse}

Copyright Status: In copyright. Digitized with the permission of the rights holder.

License: http://creativecommons.org/licenses/by-nc-sa/3.0/

Rights: https://biodiversitylibrary.org/permissions

This document was created from content at the Biodiversity Heritage Library, the world's largest open access digital library for biodiversity literature and archives. Visit BHL at https://www.biodiversitylibrary.org. 